\title{
Strain dependence electrical resistance and cohesive strength of ITO thin films deposited on electroactive polymer
}

L. Rebouta ${ }^{1}$, L. Rubio-Peña ${ }^{2}$, C. Oliveira ${ }^{1}$, S. Lanceros-Mendez ${ }^{1}$, C.J. Tavares ${ }^{1}$, E. Alves ${ }^{2}$

${ }^{1}$ Departamento de Física, Universidade do Minho, 4800-058 Guimarães, Portugal

${ }^{2}$ University of Cadiz, Engineering School, C/ Chile, 1, 11002 Cádiz, Spain

${ }^{3}$ ITN, Departamento de Física, E.N.10, 2686-953 Sacavém, Portugal

Keywords: tensile test, ITO, cohesive strength, crack onset strain, electroactive polymers

\begin{abstract}
Transparent, conducting, indium tin oxide (ITO) films have been deposited, by pulsed dc magnetron sputtering, on glass and electroactive polymer (poly (vinylidene fluoride)- PVDF) substrates. Samples have been prepared at room temperature by varying the oxygen partial pressure. Electrical resistivity around $8.4 \times 10^{-4} \Omega \mathrm{cm}$ has been obtained for films deposited on glass, while a resistivity of $1.7 \times 10^{-3} \Omega \mathrm{cm}$ has been attained in similar coatings on PVDF. Fragmentation tests were performed on PVDF substrates with thicknesses of $28 \mu \mathrm{m}$ and $110 \mu \mathrm{m}$ coated with $40 \mathrm{~nm}$ ITO layer. The coating's fragmentation process was analyzed and the crack onset strain and cohesive strength of ITO layers were evaluated.
\end{abstract}

\section{Introduction}

Indium tin oxide (ITO) thin films are widely used as transparent electrodes in optoelectronic and electro-optic devices such as solar cells and flat panel displays [1-3]. This is due to their unique properties of both a low electrical resistivity and a high transmittance in the visible spectral region [4,5]. These properties are obtained using substrate temperatures higher than $200{ }^{\circ} \mathrm{C}$, but the growing interest in flexible substrates leads to the use of polymeric substrates, which require the deposition of films at low temperature [6-9]. Further, the deposition on polymeric substrates decreases the quality of the film properties, leading to a higher roughness, higher resistivity and lower transmittance $[10,11]$.

Poly(vinylidene fluoride) - PVDF - in its $\beta$ phase is a polymeric material with electroactive properties. It combines the piro- and piezoelectric characteristics, with an excellent combination of processability, mechanical strength, lightness, moldability and low production cost. These properties allow the use of PVDF as a substrate and as an active layer in applications such as flexible touch screens and keyboards [12]. The advantage of the flexibility of the active layer can be lost due to the limited mechanical ruggedness of brittle ITO films [13]. These brittle layers are likely to be the source of failure in these flexible devices and therefore, it is important to understand and improve the mechanical limits of these materials. With this objective, fragmentation tests of 
ITO films deposited on electroactive PVDF were performed. At the same time the electrical resistance was measured, in situ, as a function of the mechanical strain.

\section{Theory}

According to the weakest link model, the cohesive strength of a coating can be evaluated from the early stages of the fragmentation process assuming a Weibull type size dependent probability of failure for the coating fragments of length $\ell$ under a stress $\sigma[14,15]$ :

$$
\mathrm{F}(\sigma)=1-\exp \left[-\frac{\ell}{\ell_{0}}\left(\frac{\sigma}{\beta}\right)^{\alpha}\right]
$$

Assuming that the residual stresses are negligible and that the coating strength follows a two parameter Weibull distribution, in the initial stage of fragmentation the average fragment length is related to the stress acting in the coating. The average fragment length $(\ell)$ in the initial stage is equal to $\ell_{0}(\sigma / \beta)^{-\alpha}$, where $\ell_{0}$ is a normalizing factor, chosen equal to $1 \mu \mathrm{m}[15], \sigma$ is the axial stress acting in the coating, and $\alpha$ and $\beta$ are the Weibull shape and scale parameters, respectively. These parameters can be derived from a linear extrapolation of the initial part of the crack density evolution, from a plot of $\ln \ell$ against $\ln \sigma[15,16]$. The cohesive strength of the coating at critical length $\left(\ell_{\mathrm{c}}\right)$ is $[15]$ :

$$
\sigma_{\max }\left(\ell_{\mathrm{c}}\right)=\beta\left(\frac{\ell_{c}}{\ell_{0}}\right)^{-1 / \alpha} \cdot \Gamma(1+1 / \alpha)
$$

where $\Gamma$ is the gamma function, $\ell_{c}=(3 / 2) \bar{\ell}$ is the critical length [17] and $\bar{\ell}$ is the experimental mean fragment length at saturation, which is also the inverse of the crack density at saturation. The crack density was calculated at each selected strain by dividing the number of tensile cracks present in the micrograph by the micrograph length and multiplying the result by $(1+\varepsilon)$ in order to consider the length increase during the test. This method considers that the internal stress of the coating is negligible. In order to take into account its influence, the internal stress should be evaluated and the crack onset strain (COS) and the coating strength obtained with this method should be corrected [16]:

$$
\begin{aligned}
& \sigma_{\max }^{\mathrm{cor}}\left(\ell_{\mathrm{c}}\right)=\sigma_{\max }\left(\ell_{\mathrm{c}}\right)+0.67 \sigma_{\mathrm{i}} \\
& \operatorname{COS}^{\mathrm{cor}}=\operatorname{COS}+\varepsilon_{i}
\end{aligned}
$$

where $\sigma_{\mathrm{i}}$ is the internal stress and $\varepsilon_{\mathrm{i}}=\sigma_{\mathrm{i}}\left(1-v_{\mathrm{c}}\right) / \mathrm{E}_{\mathrm{c}}$ is the internal strain, being $\mathrm{E}_{\mathrm{c}}$ and $v_{\mathrm{c}}$ the Young modulus and Poisson ratio of the coating.

The in plane residual stress, $\sigma_{\mathrm{i}}$, was calculated using the curvature radius of the substrate, before, $\mathrm{r}_{\mathrm{b}}$, and after, $r_{a}$, the deposition [18]: 


$$
\sigma_{\mathrm{i}}=\frac{E_{s} h_{s}^{2}}{6\left(1-v_{s}\right) h_{c}}\left(1+\frac{h_{c}}{h_{s}}\left(4 \frac{E_{c}}{E_{s}}-1\right)\right)\left(\frac{1}{r_{a}}-\frac{1}{r_{b}}\right)
$$

where $E_{s}$ is the Young modulus of the substrate, $h_{s}$ and $h_{c}$ are the thicknesses of the substrate and coating, respectively, and $v_{\mathrm{s}}$ is the Poisson ratio of the substrate.

The Young modulus of ITO was assumed to be $100 \mathrm{GPa}$ [18] and the Young modulus of the substrate was determined from the tensile testing. The Poisson ratio of the coating was assumed to be 0.3

\section{Experimental details}

ITO films have been deposited under a mixed $\mathrm{Ar} / \mathrm{O}_{2}$ atmosphere with a base pressure of $2 \times 10^{-4}$ Pa. From a 2 inch diameter ITO target, (indium oxide/tin oxide, 90/10 wt.\%) pulsed dc magnetron sputtering with a frequency of $140 \mathrm{kHz}$ and a duty cycle of 0.7 has been used. Glass and PVDF ( $\beta$ phase, $28 \mu \mathrm{m}$ and $110 \mu \mathrm{m}$ thick from Measurement Specialties) have been used as substrates. A target current density of $0.6 \mathrm{~mA} \mathrm{~cm} \mathrm{~cm}^{-2}$ has been used and a deposition rate of $21 \mathrm{~nm} / \mathrm{min}$ was obtained. A pulsed bias of $-40 \mathrm{~V}$ with a frequency of $90 \mathrm{kHz}$ was applied to the substrate holder during the depositions. The oxygen partial pressure was varied from $0.006 \mathrm{~Pa}$ to $0.020 \mathrm{~Pa}$, for a constant working pressure of $0.4 \mathrm{~Pa}$. The oxygen partial pressure is the pressure measured before starting the deposition with only the oxygen flowing to the chamber. The target-to-substrate distance was kept constant at $8 \mathrm{~cm}$ in all runs and the substrate was not heated. X-ray diffraction (XRD) has been used to examine the crystallinity and crystal orientation using $\mathrm{Cu} \mathrm{K}_{\alpha}$ radiation. (Bruker AXS Discover D8 apparatus). Glass substrates were used in these measurements in order to avoid the presence of polymer substrate peaks.

Electrical resistivity, carrier concentration and Hall mobility of the coatings on glass substrates have been measured using the Van der Pauw geometry, under a magnetic field of $1 \mathrm{~T}$. In the films over PVDF substrates, two aluminium contacts $(8 \mathrm{~mm} \times 2 \mathrm{~mm})$ separated by $1 \mathrm{~mm}$ have been deposited in order to measure the sheet resistance. The electromechanical tests were carried out on $10 \times 40 \mathrm{~mm}^{2}$ samples with a computer-controlled tensile testing machine (Minimat, Polymer Labs), which was mounted on an optical microscope stage (Nikon Optiphot-100). One of the grips of the instrument was displaced at a constant speed of $0.2 \mathrm{~mm} / \mathrm{min}$. The applied load and the stage displacement, as well as the resistance values were recorded every second. The crack development was recorded through a CCD camera connected to the microscope. The evolution of the crack density was obtained by the subsequent video analysis. The substrates curvature radii were measured with a Nikon binocular lens. 


\section{Results and discussion}

\section{Structure}

The XRD measurements displayed in Fig. 1, as a function of the oxygen partial pressure $\left(\mathrm{P}_{\mathrm{O} 2}\right)$, indicate that ITO films are either amorphous or weakly polycrystalline having lattice parameters corresponding to those of the bixbyite structure of $\operatorname{In}_{2} \mathrm{O}_{3}$ [19]. A texture is visible, although those films prepared with intermediate fluxes are almost amorphous. No $\mathrm{SnO}_{2}$ phase was found from the XRD patterns. Previous studies from other authors have shown that ITO films prepared with high energetic sputtered particles resulted in a (400) and (440) texture, while with lower energetic particles lead to the formation of a (222) texture [20]. A (222) texture was also obtained using facing target sputtering [21], where the bombardment by high energy negative oxygen ions was suppressed. The thickness of these samples is around $90 \mathrm{~nm}$, except the samples prepared with oxygen partial pressures of 0.009 and $0.011 \mathrm{~Pa}$, which have thicknesses of 119 and $107 \mathrm{~nm}$, respectively. Other results reported on the XRD analysis of ITO films indicate that the intensity of (200) and (400) peaks decreases with increasing oxygen partial pressure [22].



Fig. 1 - XRD pattern for ITO thin films prepared under different oxygen partial pressures, which are indicated in the graphs.

\section{Electrical properties}

The electrical resistivity, charge carrier concentration and Hall mobility for ITO films deposited on glass are shown in Fig. 2 as a function of the oxygen partial pressure. In the range 
used in these experiments, the resistivity of the ITO films initially decreased with increasing oxygen partial pressure and then did not show appreciable changes until a $\mathrm{P}_{\mathrm{O} 2}$ of $0.02 \mathrm{~Pa}$. A further increase of $\mathrm{P}_{\mathrm{O} 2}$ normally corresponds in an increase of the resistivity. The minimum value for the film resistivity is $8.4 \times 10^{-4} \Omega \cdot \mathrm{cm}$, and was obtained at a $\mathrm{P}_{\mathrm{O} 2}$ of $0.013 \mathrm{~Pa}$ and for an $\mathrm{XRD}$ amorphous structure. Other studies on TCO films prepared without intentional substrate heating also obtained the lowest resistivity for coatings with amorphous structure [8, 23]. A similar behaviour was found with films deposited on PVDF with the minimum resistivity of $1.7 \times 10^{-3} \Omega \mathrm{cm}$ obtained for samples prepared with $0.011 \mathrm{~Pa}$ and $0.013 \mathrm{~Pa}$.



Fig. 2 - Evolution of the resistivity ( $\mathbf{a})$, carrier concentration $(\times)$ and Hall mobility $(\circ)$ of ITO coated glass as a function of the oxygen partial pressure during deposition, at a working pressure of $0.04 \mathrm{~Pa}$.

The carrier concentration does not show a clear tendency, and changed between $1.4 \times 10^{20}$ and $2.8 \times 10^{20} \mathrm{~cm}^{-3}$. The number of carriers arises from oxygen vacancies or from Sn ions on In sites. It was expected that an increase in $\mathrm{P}_{\mathrm{O} 2}$ would lead to a decrease in the number of oxygen vacancies acting as ionized donors in the film, which would lead to a decrease in carrier density. However, this was not clearly detected in these experiments. These results can be explained if in addition we have the activation of the $\mathrm{Sn}$ donors. When increasing $\mathrm{P}_{\mathrm{O} 2}$ to $0.020 \mathrm{~Pa}$, the Hall mobility shows a continuous increase from 8 to $40 \mathrm{~cm}^{2} \mathrm{~V}^{-1} \mathrm{~s}^{-1}$. The increase in mobility might be due to a decrease in the number of oxygen vacancies acting as scattering centers and can be related with the decrease of the crystalline fraction present in the film, as shown in the XRD results. The initial decrease in resistivity resulted from an increase in mobility with increasing $\mathrm{P}_{\mathrm{O} 2}$ until $0.013 \mathrm{~Pa}$, due to the suppression of crystallite grain boundaries and subsequent decrease in electron scattering, while, for a further increase in $\mathrm{P}_{\mathrm{O} 2}$, the increase in resistivity at $0.015 \mathrm{~Pa}$ can be explained by resulting from the decrease of the carrier concentration due to the reduction of oxygen vacancies. 
In the case of coatings deposited on PVDF, the minimum value for the film resistivity was $1.7 \times 10^{-3} \Omega \cdot \mathrm{cm}$. The roughness of the PVDF substrate leads to a higher resistivity when compared to the values obtained for films deposited on glass [24].

\section{Tensile tests}

The tensile tests were performed with PVDF substrates with thicknesses of 28 and $110 \mu \mathrm{m}$ coated with ITO films prepared with two different oxygen partial pressures $(0.011 \mathrm{~Pa}$ and $0.020 \mathrm{~Pa})$ and thicknesses around $40 \mathrm{~nm}$. In order to obtain the $\beta$-phase, the PVDF substrate, was stretched during its processing, being the stretching relation between the initial and the final length of the sample from 4 to 7 [25]. The PVDF substrate is anisotropic and the elastic moduli of parallel and perpendicular directions (to the stretching direction) are $1.2 \mathrm{GPa}$ and $1.5 \mathrm{GPa}$, respectively. The elongation direction of the stress-strain curves was along the stretching direction.

During straining, the surface of the polymer/coating composites was analyzed by an optical microscope. The surface of the as deposited ITO coatings bore the presence of some defects, such as those shown in Fig. 3, which resulted in nucleation sites for the initiation of the cracks. Fig. 4 shows optical micrographs of $\operatorname{PVDF}(110 \mu \mathrm{m}) / \mathrm{ITO}(0.020 \mathrm{~Pa})$ and $\operatorname{PVDF}(28 \mu \mathrm{m}) / \mathrm{ITO}(0.011 \mathrm{~Pa})$ systems that illustrate the fragmentation process performed at room temperature, under constant strain rate. The arrows indicate the elongation direction and the strain values are indicated in the optical micrograph. The first cracks were identified for a nominal strain of about $2.2 \%$ and the number of cracks increased rapidly until a nominal strain of about $3.5 \%$.

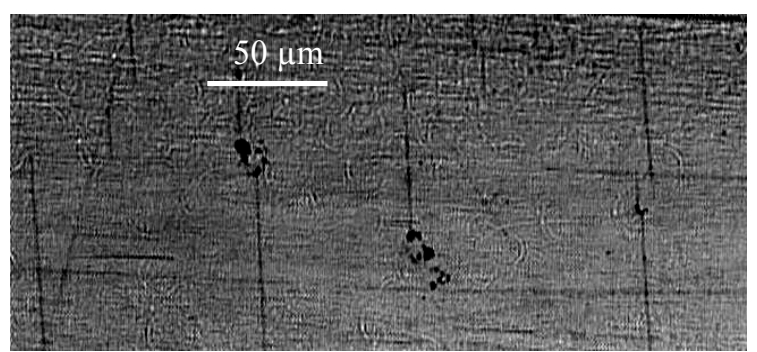

Fig. 3 - Crack pattern of an ITO coated PVDF substrate showing the presence of surface defects, where the first cracks are initiated. The arrows indicate the elongation direction.

The transverse cracking of the fragments was initiated at about $6 \%$ strain for PVDF $(110 \mu \mathrm{m})$ and about $5 \%$ strain for PVDF $(28 \mu \mathrm{m})$. The development of these cracks is due to the lateral contraction of the sample, which results from Poisson effects [17]. The evolution of the crack density and electrical resistance $(\Delta \mathrm{R} / \mathrm{R})$ is shown in Fig. 5. The crack onset strain is similar for the different ITO coatings and also it is not affected by the substrate thickness (28 and $110 \mu \mathrm{m})$ either. The coatings have similar properties and similar thicknesses, and the small differences can only cause changes that are within the uncertainty of the experimental method. 
With respect to the evolution of the electrical resistance, in all cases the resistance increases sharply, which is consistent with other studies of thin ceramic coatings deposited on flexible substrates $[18,26]$. The increase in the resistance is due to the formation of cracks created by the applied load, as shown in Fig. 4, and it is related with the cohesive strength of the film. The sudden increase in the resistance of the sample between 2 and $2.5 \%$ strain correlates with the onset of cracks (see Fig. 5). A similar behaviour was observed in all samples shown in Fig. 5. With a relatively high crack density the resistance remains finite, suggesting that the cracks do not cut completely the conducting paths.

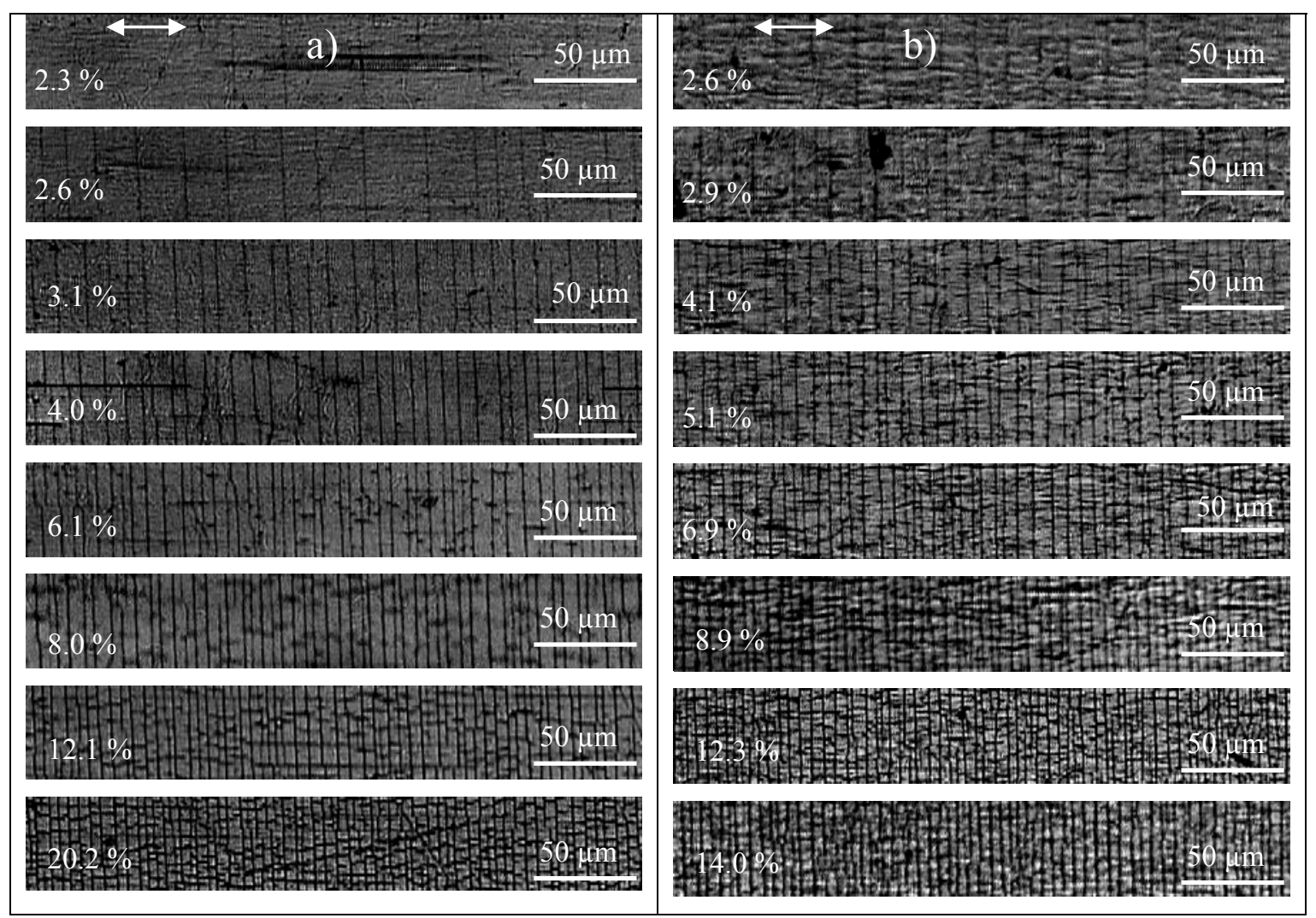

Fig. 4 - Crack patterns of ITO coated PVDF substrate for increasing nominal strains. The arrows indicate the elongation direction and the strain values are indicated in the optical micrograph: a) PVDF $(110 \mu \mathrm{m}) / \mathrm{ITO}(0.020 \mathrm{~Pa})$; b) PVDF $(28 \mu \mathrm{m}) / \mathrm{ITO}(0.011 \mathrm{~Pa})$.

The values of the parameters $\alpha$ and $\beta$ of the Weibull distribution of PVDF/ITO coatings were evaluated from the plot of $\ln (\bar{\ell})$ against $\ln (\sigma)$, and are presented in table I, together with the cohesive strength of the ITO coatings at critical length obtained with eq. (2). The internal stress of the coatings was evaluated using the eq. (5) and was used to calculated the intrinsic crack onset strain $\left(\mathrm{COS}^{\mathrm{cor}}\right)$ and intrinsic cohesive strength of ITO films using the eq. (3) and (4). The crack onset strains are relatively higher than those reported in literature for ITO films. For example, Leterrier et al. reported an intrinsic $\operatorname{COS}^{\mathrm{cor}}$ of $1.61 \%$ for an amorphous ITO layer with a thickness of $50 \mathrm{~nm}$ and lower values $(<1.2 \%)$ for thicker and polycrystalline films [18]. Although similar results have been obtained in additional tests with samples prepared in the same conditions, in order 
to identify the source of this discrepancy (substrate type, microstructural variations and/or experimental procedure) more experiments will be necessary.
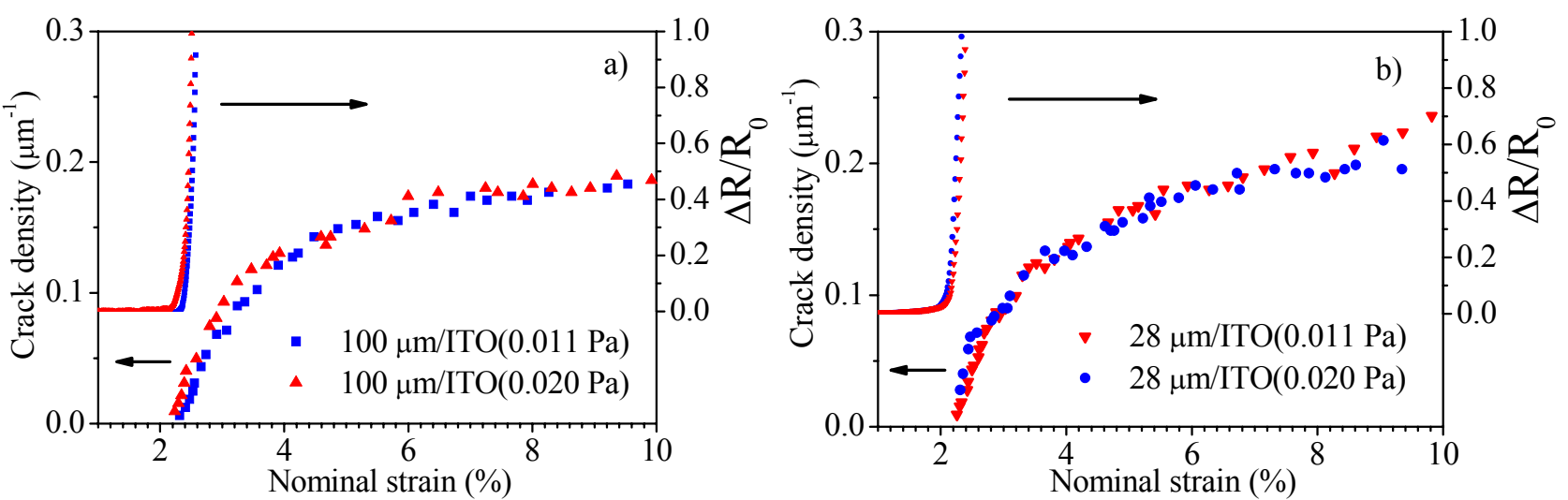

Fig. 5 - Crack density and change in resistance $(\Delta R / R)$ as a function of the substrate nominal strain for different ITO coatings deposited on: a) PVDF $110 \mu \mathrm{m}$; b) PVDF $28 \mu \mathrm{m}$.

Table I - Crack onset strain (COS), crack density at saturation (CDS), shape parameters of the Weibull distribution $\left(\alpha\right.$ and $\beta$ ) of PVDF/ITO coatings, critical length $\left(\ell_{c}\right)$ and cohesive strength $\left(\sigma_{\max }\left(\ell_{c}\right)\right)$ of the ITO coatings.

\begin{tabular}{|c|c|c|c|c|c|c|c|c|}
\hline Sample & $\begin{array}{c}\text { CDS } \\
\left(\mu \mathrm{m}^{-1}\right)\end{array}$ & $\begin{array}{c}\text { COS } \\
(\%)\end{array}$ & $\begin{array}{c}\mathrm{COS}^{\text {cor }} \\
(\%)\end{array}$ & $\alpha$ & $\begin{array}{c}\beta \\
(\mathrm{GPa})\end{array}$ & $\begin{array}{c}\ell \mathrm{c} \\
(\mu \mathrm{m})\end{array}$ & $\begin{array}{c}\sigma_{\max }\left(\ell_{\mathrm{c}}\right) \\
(\mathrm{GPa})\end{array}$ & $\begin{array}{c}\sigma_{\max }^{\text {cor }}\left(\ell_{\mathrm{c}}\right) \\
(\mathrm{GPa})\end{array}$ \\
\hline PVDF $(110 \mu \mathrm{m}) / \mathrm{ITO}(0.020 \mathrm{~Pa})$ & $0.26 \pm 0.01$ & $2.2 \pm 0.2$ & $2.1 \pm 0.2$ & 12.1 & 3.49 & 5.8 & 2.9 & 2.7 \\
\hline PVDF $(110 \mu \mathrm{m}) / \mathrm{ITO}(0.011 \mathrm{~Pa})$ & $0.22 \pm 0.01$ & $2.3 \pm 0.2$ & $2.2 \pm 0.2$ & 14.3 & 3.60 & 6.8 & 3.0 & 2.8 \\
\hline PVDF $(28 \mu \mathrm{m}) / \mathrm{ITO}(0.020 \mathrm{~Pa})$ & $0.22 \pm 0.02$ & $2.2 \pm 0.2$ & $2.1 \pm 0.2$ & 12.7 & 3.36 & 6.9 & 2.8 & 2.6 \\
\hline PVDF $(28 \mu \mathrm{m}) / \mathrm{ITO}(0.011 \mathrm{~Pa})$ & $0.28 \pm 0.02$ & $2.2 \pm 0.2$ & $2.1 \pm 0.2$ & 15.0 & 3.36 & 5.3 & 2.9 & 2.7 \\
\hline
\end{tabular}

\section{Summary}

Uniaxual tensile tests for amorphous ITO films deposited on PVDF substrates have been performed and the crack onset strain, the evolution of the crack density and electrical resistance were measured and analyzed. The first cracks were identified for a nominal strain of $\sim 2.1 \%$, which is correlated with the sudden increase in the resistance of the sample. The cohesive strength of the coatings with a thickness of $\sim 40 \mathrm{~nm}$ was determined to be $2.7 \mathrm{GPa}$.

\section{Acknowledgements}

The authors appreciate the funding from the Portuguese Foundation for Science and Technology (FCT) (Grant PTDC/CTM/69316/2006) and INL project 156: SIMBIO.

\section{References}


[1] M. Fonrodona, J. Escarré, F. Villar, D. Soler, J.M. Asensi, J. Bertomeu, J. Andreu: Solar Energy Mater. \& Solar Cells 89 (2005)

[2] C.G. Granqvist, A. Hultåker, Thin Solid Films 411 (2002) 1

[3] Y. Hong, Z. He, N.S. Lennhoff, D.A. Banach, J. Kanicki, J. Electronic Materials, 33 (2004) 312

[4] I. Hamberg, C.G. Granqvist: J. Appl. Phys. 60 (1986) R123

[5] G.J. Exarhos, X.-D. Zhou, Thin Solid Films 515 (2007) 7025

[6] H.-Y. Yeom, N. Popovich, E. Chason, D. C.Paine, Thin Solid Films 411 (2002) 17

[7] Y. Hoshi, T. Kiyomura, Thin Solid Films 411 (2002) 36

[8] D. Mergel, M. Schenkel, M. Ghebre, M. Sulkowski, Thin Solid Films 392 (2001) 91

[9] Li-jian Meng, M.P. dos Santos, Appl. Surf. Science 120 (1997) 243

[10] B.G. Lewis, D.C. Paine, MRS Bull. 25 (2000)

[11 P.F. Garcia, R.S. McLean, M.H. Reilly, Z.G. Li, L.J. Pillione, R.F. Messier, Appl. Phys. Lett. 81 (2002) 1800

[12] Nalwa, H. S., Ferroelectric Polymers: Chemistry, Physics, and Applications, Vol 1 (Ed. Marcel Dekker, Inc, New York, 1995)

[13] J. Lewis, Materials Today, 9 (2006) 38

[14] W. Weibull, J.Appl. Mech. 18 (1951) 293

[15] Y. Leterrier, L. Boogh, J. Andersons, J.-A.E. Månson, J. Polym. Sci. B: Polym. Phys. 35

(1997) 1449

[16] Y. Leterrier, Prog. Mater. Sci. 48 (2003) 1

[17] Y. Leterrier, Y. Wyser, J.-A.E. Månson, J. Hilborn, J. Adhesion, 44 (1994) 213

[18] Y. Leterrier, L. Médico, F. Demarco, J.-A.E. Månson, U. Betz, M.F. Escola, M.K. Olsson, F. Atamny, Thin Solid Films 460 (2004) 156

[19] Powder Difraction file JCPDS-ICDD (1991) 6-416

[20] C.V.R. Kumar, A. Mansignh, J.Appl. Phys. 65 (1989) 1270

[21] Y. Hoshi, H. Kato, K. Funatsu, Thin Solid Films 445 (2003) 245

[22] J. Dietrich, K. Schmalzbauer, H. Hoffmann, J. Szczyrbowski, Thin Solid Films 122 (1984) 19

[23] E. Fortunato, A. Pimentel, A. Gonçalves, A. Marques, R. Martins, Thin Solid Films 502

(2006) 104

[24] C. Oliveira, L. Rebouta, T. de Lacerda-Arôso, S. Lanceros-Mendez, T. Viseu, C.J. Tavares, J. Tovar, S. Ferdov, E. Alves, Thin Solid Films 517 (2009) 6290

[25] V. Sencadas, R. Gregorio Jr., S. Lanceros-Méndez, J. Macromolecular Science , Part B:

Physics, 48 (2009) 514

[26] D.R. Cairns, R.P. Witte II, D.K. Sparacin, S.M. Sachsman, D.C. Paine, G.P. Crawford, Appl. Phys. Lett., 76 (2000) 1425 